\title{
Activation of $\mathrm{S1P}_{2}$ receptor, a possible mechanism of inhibition of adipogenic differentiation by sphingosine 1-phosphate
}

\author{
MYUNG-HEE MOON, JAE-KYO JEONG and SANG-YOUEL PARK \\ Biosafety Research Institute, College of Veterinary Medicine, \\ Chonbuk National University, Jeonju, Jeonbuk 561-756, Republic of Korea
}

Received March 19, 2014; Accepted August 29, 2014

DOI: $10.3892 / \mathrm{mmr} .2014 .2810$

\begin{abstract}
Sphingosine 1-phosphate (S1P) belongs to a significant group of signaling sphingolipids and exerts most of its activity as a ligand of G-protein-coupled receptors. In our previous study, S1P demonstrated a novel biological activity with the anti-adipogenesis of 3T3-L1 preadipocytes. In the present study, we identified a possible mechanism of S1P-mediated anti-adipogenic effects, particularly in target pathways of the $\mathrm{S} 1 \mathrm{P}$ receptors, including $\mathrm{S}_{1} \mathrm{P}_{1}$ and $\mathrm{S}_{1} \mathrm{P}_{2}$. The mRNA levels of $\mathrm{S}_{1} \mathrm{P}_{1}$ and $\mathrm{S}_{1} \mathrm{P}_{2}$ receptors were increased by MDI media treatment, whereas S1P treatment highly induced $\mathrm{S}_{1} \mathrm{P}_{2}$ but not $\mathrm{S}_{1} \mathrm{P}_{1}$ receptor protein in adipocytes. Triglyceride accumulation assay using an agonist and antagonist of $\mathrm{S} 1 \mathrm{P}$ receptors revealed that $\mathrm{S}_{\mathrm{P}} \mathrm{P}_{2}$ receptor was only involved in S1P-mediated anti-adipogenic effects. Furthermore, pharmacological inhibition of $\mathrm{S}_{1} \mathrm{P}_{2}$ signals completely retrieved S1P-mediated downregulation of the transcriptional levels of peroxisome proliferator-activated receptor $\gamma$, CCAAT/enhancer binding protein $\alpha$ and adiponectin, which are markers of adipogenic differentiation. This study demonstrated that $\mathrm{S}_{\mathrm{P}}$ receptor signals may regulate the S1P-mediated anti-adipogenic differentiation and also identifies the $\mathrm{S}_{1} \mathrm{P}_{2}$ receptor as a possible mechanism of anti-adipogenic differentiation.
\end{abstract}

Correspondence to: Professor Sang-Youel Park, Biosafety Research Institute, College of Veterinary Medicine, Chonbuk National University, Duk-Jin Dong 1 Ga 664-14, Jeonju, Jeonbuk 561-756, Republic of Korea

E-mail: sypark@chonbuk.ac.kr

Abbreviations: S1P, sphingosine 1-phosphate; PPAR $\gamma$, peroxisome proliferator-activated receptor $\gamma ; \mathrm{C} / \mathrm{EBP} \alpha, \mathrm{CCAAT} / \mathrm{enhancer}^{-}$ binding protein $\alpha$

Key words: sphingosine 1-phosphate, ${\mathrm{S} 1 \mathrm{P}_{2}}_{2}$ receptor, 3T3-L1, adipocyte, differentiation

\section{Introduction}

Sphingolipids are ubiquitous components of eukaryotic cell membranes, which can be metabolized to ceramide, sphingosine and their phosphorylated forms, including ceramide 1-phosphate (C1P) and sphingosine 1-phosphate (S1P), which possess bioactivity and vital biological functions in cell growth and survival (1). Experimental studies have denoted $\mathrm{S} 1 \mathrm{P}$ as one of the most significant sphingolipid metabolites (2). S1P plays various roles in physiological processes, promotes cellular proliferation, stimulates cell survival and protects cells against apoptosis through G-protein-coupled receptors (GPCRs) or an intracellular receptor-independent mechanism $(3,4)$.

Obesity represents a major risk factor of cardiovascular and endocrine-related diseases, and is defined as an excessive deposit of adipose tissue and cholesterol. Adipogenesis is the process whereby preadipocytes undergo differentiation into mature adipocytes. Adipocytes are derived from mesenchymal stem cells, which have the potential to differentiate into myoblasts, chondroblasts, osteoblasts or adipocytes (5). Adipocyte differentiation involves an elaborate network of transcription factors that regulate the expression of numerous genes responsible for the phenotype of mature adipocytes (6). The main transcription factor that mediates preadipocyte differentiation is peroxisome proliferator-activated receptor $\gamma$ $(\operatorname{PPAR} \gamma)$, which is considered the 'master regulator of adipogenesis'. Other adipogenic transcription factors include the $\mathrm{CCAAT} /$ enhancer binding proteins $(\mathrm{C} / \mathrm{EBP} \alpha, \mathrm{C} / \mathrm{EBP} \beta$ and $\mathrm{C} / \mathrm{EBP} \gamma)(6-8)$.

The ATP-dependent phosphorylated form of sphingosine, S1P, may only be produced from sphingosine by sphingosine kinases, and S1P phosphatase dephosphorylates S1P to sphingosine $(9,10)$. Acylation of sphingosine and other long-chain base sphingolipids leads to the formation of ceramide in the turnover pathway (11). S1P has been identified in numerous mammalian cells and other organisms, and harbors distinctive biological functions (13).

Sphingolipids have emerged as multifunctional intra- and intercellular signal-transducing molecules, in addition to performing their well-established roles as structural components of cellular lipid membrane bilayers. S1P belongs to a significant group of signaling sphingolipids recognized to play a role in a diverse array of cellular processes, including 
apoptosis, cell motility, differentiation and proliferation in a variety of cell types, including endothelial cells, smooth muscle cells and macrophages $(14,15)$.

$\mathrm{S} 1 \mathrm{P}$ is generated by the phosphorylation of the sphingosine mediated by sphingosine kinases 1 (Sphk-1) and 2 (Sphk-2) (16). These two isoforms have been identified in mammals. Sphk enzyme activity is expressed in various cell types, and is dynamically regulated by various extracellular stimuli. S1P exerts most of its activity as a ligand of GPCRs (17). Chemotherapy induces downregulation of S1P by inhibiting Sphk. Lowering of the circulating S1P by chemotherapy may switch S1P-mediated adipose cell stasis to adipogenesis. However, the signal pathways of S1P and the S1P receptors in the differentiation of preadipocytes in the context of cellular physiology remain largely unknown.

In the present study, we examined the hypothesis that $\mathrm{S} 1 \mathrm{P}$ regulates adipogenic differentiation and modulates its functions via $\mathrm{S} 1 \mathrm{P}$ receptor $2\left(\mathrm{~S}_{\mathrm{P}}\right)$. We provide evidence that the adipogenesis of cultured mouse 3T3-L1 preadipocytes is correlated with the $\mathrm{S}_{1} \mathrm{P}_{2}$ receptor, and further demonstrate that pharmacological inhibition of $\mathrm{S}_{1} \mathrm{P}_{2}$ signals completely retrieved S1P-mediated downregulation of the transcriptional levels of PPAR $\gamma, \mathrm{C} / \mathrm{EBP} \alpha$ and adiponectin, which are markers of adipogenic differentiation.

\section{Materials and methods}

Reagents. S1P was purchased from Cayman Chemical (Ann Arbor, MI, USA) and Sigma-Aldrich (St. Louis, MO, USA). S1P was prepared as a $2-\mathrm{mM}$ solution in $0.3 \mathrm{M} \mathrm{NaOH}$ and then further diluted in cell culture medium. SEW2871, a $\mathrm{S}_{1} \mathrm{P}_{1}$ agonist, and $\mathrm{W} 146$, a $\mathrm{S}_{1} \mathrm{P}_{1}$ antagonist, were purchased from Cayman Chemical. The $\mathrm{S}_{2} \mathrm{P}_{2}$ JTE-013 antagonist (Cayman Chemical) was prepared as a $2-\mathrm{mM}$ solution in ethanol and then further diluted in cell culture medium. Anti-S1P2 goat polyclonal antibody was purchased from Santa Cruz Biotechnology, Inc. (Santa Cruz, CA, USA).

Cell culture and differentiation. The 3T3-L1 cells were obtained from the American Type Culture Collection (Manassas, VA, USA) and maintained in Dulbecco's modified Eagle's medium (DMEM) containing $10 \%$ calf serum and antibiotics $\left(100 \mu \mathrm{g} \cdot \mathrm{ml}^{-1}\right.$ gentamycin and $100 \mu \mathrm{g} \cdot \mathrm{ml}^{-1}$ penicillin-streptomycin). To induce differentiation, 2-day postconfluent 3T3-L1 cells were incubated in MDI induction medium (DMEM containing 10\% fetal bovine serum, $0.5 \mathrm{mM} 3$-isobutyl-1-methylxanthine, $1 \mu \mathrm{m}$ dexamethasone and $1 \mu \mathrm{g} / \mathrm{ml}$ insulin) for 2 days. In certain experiments, S1P (10 $\mu \mathrm{M}$ ), SEW2871 (from 0.1 to $50 \mu \mathrm{M}$ ), W146 (from 0.01 to $10 \mu \mathrm{M}$ ) and JTE-013 (from 0.02 to $2 \mu \mathrm{M}$ ) were added at the time of the induction of differentiation. Two days after MDI media treatment (day 2), the cell number was determined by a trypan blue exclusion test (Life Technologies, Grand Island, NY, USA) and the medium was changed to insulin medium. The AdipoRed assay and detection of glycerol release contents were performed on day 7 .

Quantification of lipid content. Lipid content was quantified using the commercially available AdipoRed assay reagent (Lonza, Verviers, Belgium) according to the manufacturer's instructions. In brief, preadipocytes grown in 24-well plates were incubated with MDI medium or test compounds, including S1p, SEW2871, W146 and JTE-013, during the adipogenic phase and, on day 7, culture supernatant was removed and the cells were carefully washed with $500 \mu$ l phosphate-buffered saline (PBS). The wells were then filled with $300 \mu \mathrm{l} \mathrm{PBS}$, and $30 \mu \mathrm{l}$ AdipoRed reagent was added and incubated for $10 \mathrm{~min}$ at $37^{\circ} \mathrm{C}$. Fluorescence was measured with an excitation of $485 \mathrm{~nm}$ and emission of $572 \mathrm{~nm}$.

Real-time polymerase chain reaction (PCR). Total RNA was extracted from 3T3-L1 cells treated with S1P using the Easy-spin ${ }^{\mathrm{TM}}$ total RNA extraction kit (Intron Biotechnology, Seoul, Korea). cDNA synthesis was carried out following the instructions of the Takara PrimeScript ${ }^{\mathrm{TM}}$ First Strand cDNA synthesis kit (Takara Bio, Tokyo, Japan). For real-time PCR, $1 \mu 1$ gene primers with SYBR-Green (Bio-Rad Laboratories, Hercules, CA, USA) in $20 \mu \mathrm{l}$ reaction volume was applied. The sequences of the primers used for real-time PCR were as follows: $\mathrm{S}_{1} \mathrm{P}_{1}$ (forward, 5'GAAACTACACAACGGGAG CAACAG3' and reverse, 5'AAGCAGGAGCAGAGTGAAGACG3'), S1 $P_{2}$ (forward, 5'AACAGCAAGTTCCACTCAGCAATG3' and reverse, 5'GGCGGAGAGCGTGATGAAGG3'), PPAR $\gamma$ (forward, 5'CGGAAGCCCTTTGGTGACTTTATG3' and reverse, 5'GCAGCAGGTTGTCTTGGATGTC3'), C/EBP $\alpha$ (forward, 5'CGGGAACGCAACAACATCGC3' and reverse, 5'TGTCCAGTTCACGGCTCAGC3'), adiponectin (forward, 5'TGACGGCAGCACTGGCAAG3' and reverse, 5'TGATACTGGTCGTAGGTGAAGAGAAC3'), $\beta$-actin (forward, 5'TGAGAGGGAAATCGTGCGTGAC3' and reverse, 5'GCTCGTTGCCAATAGTGATGACC3'). All reactions with iTaq SYBR-Green Supermix were performed on the CFX96 real-time PCR detection system (Bio-Rad Laboratories).

Western blot analysis. The 3T3-L1 cells were lysed in a lysis buffer (25 mM HEPES; pH 7.4, 100 mM NaCl, 1 mM EDTA, $5 \mathrm{mM} \mathrm{MgCl} 2,0.1 \mathrm{mM}$ dithiothreitol and protease inhibitor mixture). Proteins were electrophoretically resolved on an $8-15 \%$ sodium dodecyl sulfate gel, and immunoblotting was performed as previously described (18). Images were captured using the Fusion FX7 acquisition system (Vilbert Lourmat, Eberhardzell, Germany). The antibodies used for immunoblotting were PPAR $\gamma, \mathrm{S} 1 \mathrm{P}_{1}, \mathrm{~S}_{\mathrm{P}} \mathrm{P}_{2}$ (Santa Cruz Biotechnology, Inc.) and $\beta$-actin (Sigma-Aldrich).

Statistical evaluation. All data are expressed as the mean \pm SEM, and the data were compared using Student's t-test, analysis of variance and Duncan's multiple range test, with the SAS statistical package (SAS Institute, Inc., Cary, $\mathrm{NC}$, USA). $\mathrm{P}<0.05$ and $\mathrm{P}<0.01$ were considered to indicate a statistically significant difference.

\section{Results}

$S 1 P_{1}$ and $S 1 P_{2}$ receptor expression in preadipocytes and differentiated adipocytes. When 3T3-L1 cells were differentiated for over 6 days in the presence of S1P, lipid accumulation was reduced dose-dependently (Fig. 1A). The biological action 




Figure 1. Sphingosine 1-phosphate (S1P) inhibits lipid accumulation and detection of mRNA and protein for $\mathrm{S}_{1} \mathrm{P}_{1}$ and $\mathrm{S}_{\mathrm{P}} \mathrm{P}_{2}$ receptors. (A) Preadipocytes were induced to differentiate with increasing concentrations of S1P. ${ }^{*} \mathrm{P}<0.05$ and ${ }^{* *} \mathrm{P}<0.01$. (B) Real-time polymerase chain reaction was performed from $1 \mu \mathrm{g}$ total RNA extracted from 3T3-L1 preadipocytes and differentiated adipocytes. M, marker; CON, control; MDI, MDI induction media treatment. (C) Preadipocytes were induced to differentiate with or without $10 \mu \mathrm{M} \mathrm{S1P}$ harvested at 3,6 and $12 \mathrm{~h}$ during the differentiation period. S1P $\mathrm{P}_{1}$ and $\mathrm{S}_{1} \mathrm{P}_{2}$ receptor were analyzed by immunoblot assay with antibodies specific to $\mathrm{S}_{1} \mathrm{P}_{1}$ and $\mathrm{S}_{1} \mathrm{P}_{2}$ receptor.

of S1P is largely ascribed to ligation to specific S1PRs, which evokes distinct biological responses. To assess which receptor is associated with the S1P anti-adipogenic effect, the expression pattern of the known S1P-specific receptors was studied in the 3T3-L1 cells following the addition of MDI (Fig. 1B and C). As shown in Fig. 1B, the preadipocytes and differentiated adipocytes expressed mRNA for $\mathrm{S}_{1} \mathrm{P}_{1}$ and $\mathrm{S} 1 \mathrm{P}_{2}$ receptors, as indicated by the presence of 199- and 174-bp bands, respectively. In addition, the treatment of S1P increased the protein expression of $\mathrm{S}_{1} \mathrm{P}_{2}$ receptor (Fig. 1C). These results indicated that preadipocytes and differentiated adipocytes express $\mathrm{S}_{1} \mathrm{P}_{1}$ and $\mathrm{S}_{1} \mathrm{P}_{2}$ receptor, which are known to be associated with cell differentiation, and these receptors may be correlated with the anti-adipogenic function of S1P.

$S 1 P_{1}$ receptor does not affect adipogenic differentiation. To test the involvement of the $\mathrm{S}_{1} \mathrm{P}_{1}$ receptor in anti-adipogenic differentiation, 3T3-L1 preadipocytes were stimulated with

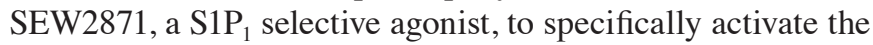
$\mathrm{S} 1 \mathrm{P}_{1}$ receptor. As shown in Fig. $2 \mathrm{~A}$ and $\mathrm{B}$, SEW2871 had no effect on the adipocyte differentiation inhibitory action of S1P. In addition, the inhibitory action of S1P on lipid accumulation was not restored by blocking the $\mathrm{S}_{1} \mathrm{P}_{1}$ receptor using $\mathrm{W} 146$, a selective $\mathrm{S} \mathrm{P}_{1}$ antagonist (Fig. $2 \mathrm{C}$ and $\mathrm{D}$ ). These results demonstrate that the anti-adipogenic action of S1P does not occur through the $\mathrm{S}_{1} \mathrm{P}_{1}$ receptor.

Adipogenic differentiation is regulated via activation of the $\mathrm{SIP}_{2}$ receptor and blockade of the $\mathrm{SIP}_{2}$ receptor using $\mathrm{SIP}_{2}$ antagonist. To determine whether the $\mathrm{S}_{1} \mathrm{P}_{2}$ receptor was involved in the anti-adipogenic activity of $\mathrm{S} 1 \mathrm{P}$, adipocyte differentiation was analyzed in mouse 3T3-L1 preadipocytes. Day 0 postconfluent 3T3-L1 preadipocytes were induced to differentiate into adipocytes using the standard differentiation protocol and co-treatment with $\mathrm{S}_{2} \mathrm{P}_{2}$ antibody, dose-dependently $(0.05-0.4 \mu \mathrm{g})$, or S1P $(10 \mu \mathrm{M})$. The effect of $\mathrm{S} 1 \mathrm{P}_{2}$ antibody was significant at $0.1 \mu \mathrm{g}$ and was maximal at $0.4 \mu \mathrm{g}$, having the same anti-adipogenic effect of $10 \mu \mathrm{M}$ S1P (Fig. 3A and B). Differentiation of the preadipocytes was induced by MDI treatment and co-treatment with JTE013 as a $\mathrm{S}_{2} \mathrm{P}_{2}$ antagonist at various doses (from $0.02 \mu \mathrm{M}$ to $2 \mu \mathrm{M}$ ) and/or $10 \mu \mathrm{M} \mathrm{S1P}$ during the adipogenesis period. When JTE013 was added to the cultures, the reduction of lipid accumulation by S1P, compared with the MDI control, was restored as treatment with JTE013 increased (Fig. 3C and D). The effect of JTE013 was significant at $0.2 \mu \mathrm{M}$ and was maximal at $2 \mu \mathrm{M}$. At $0.2 \mu \mathrm{M}$ JTE013, lipid accumulation returned to the triglyceride level of the MDI control. Moreover, $2 \mu \mathrm{M}$ of JTE013 increased lipid accumulation compared with MDI induction only. A single treatment of JTE013 alone enhanced adipocyte differentiation (Fig. 3C and D).

S1P induces downregulation of PPAR $\gamma, C / E B P \alpha$ and adiponectin expression. Next, the mRNA levels of the key genes of differentiation were examined to evaluate the effects of S1P on the regulation of the main transcriptional factors in adipogenesis via the $\mathrm{S}_{1} \mathrm{P}_{2}$ receptor. The 3T3-L1 cells underwent differentiation with MDI treatment and were co-treated with $10 \mu \mathrm{M} \mathrm{S1P}$ and/or $0.2 \mu \mathrm{M}$ JTE013. After two days, the cells were collected for real-time PCR. A reduction in the mRNA levels of PPAR $\gamma, \mathrm{C} / \mathrm{EBP} \alpha$ and adiponectin was observed with the addition of S1P; however, the $\mathrm{S}_{1} \mathrm{P}_{2}$ antagonist effectively restored the mRNA levels of PPAR $\gamma, \mathrm{C} / \mathrm{EBP} \alpha$ and adiponectin 


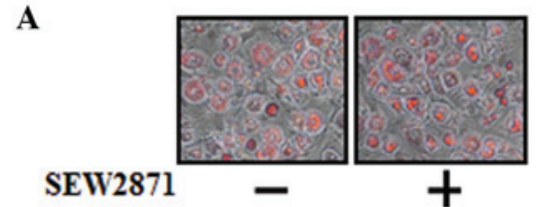

B
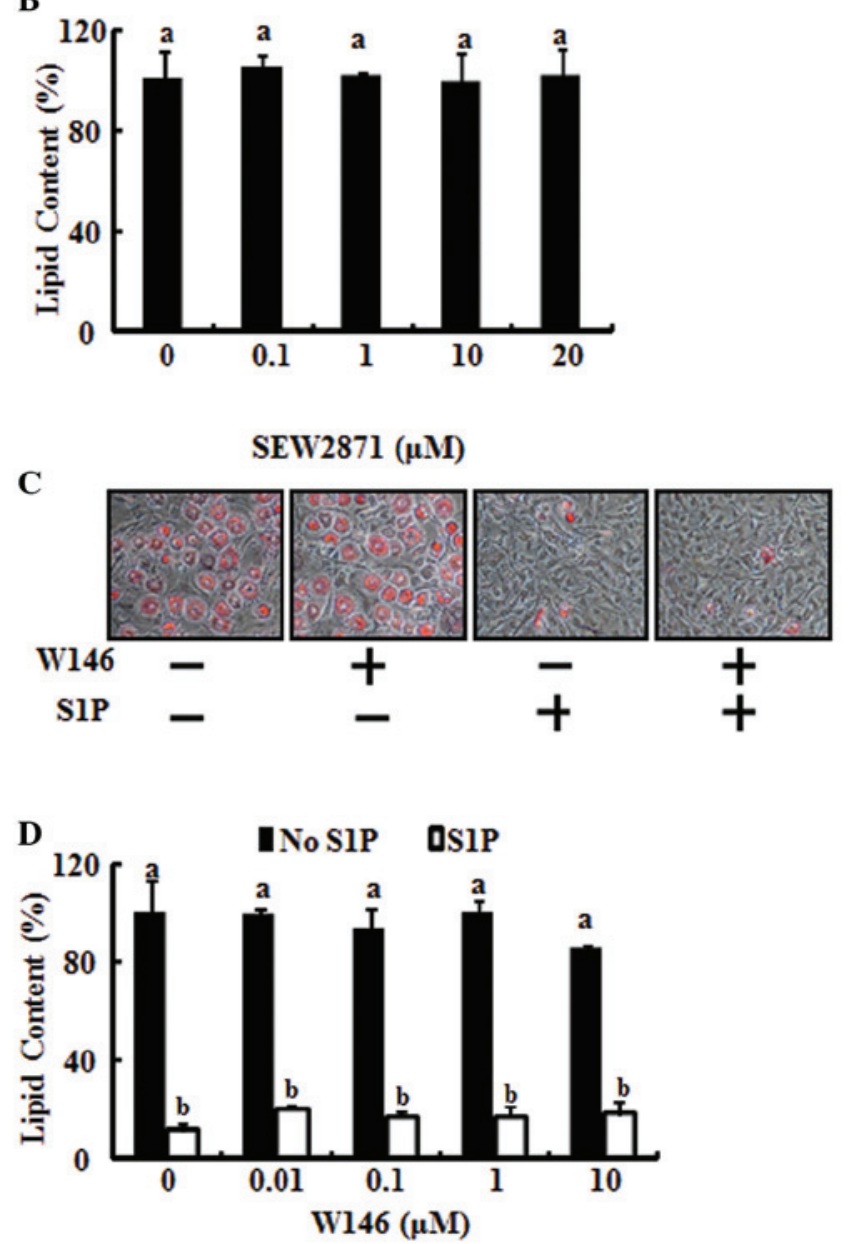

Figure 2. Sphingosine 1-phosphate receptor $1\left(\mathrm{~S}_{1} \mathrm{P}_{1}\right)$ is not correlated with the anti-adipogenic effects of S1P. (A-D) Preadipocytes were induced to differentiate with SEW2871 (A and B), known as $\mathrm{S1P}_{1}$ receptor selective agonist, or $\mathrm{W} 146$ (C and D), known as $\mathrm{S}_{1} \mathrm{P}_{1}$ receptor antagonist, at increasing concentrations for 6 days. (A and C) The AdipoRed assays (Lonza, Verviers, Belgium) were performed on day 6 and captured with a light microscope (magnification, x200). (B and D) Fluorescence was measured with excitation of $485 \mathrm{~nm}$ and emission of $572 \mathrm{~nm}$. The bar graphs indicate the mean $\pm \operatorname{SEM}(n=3)$. The data were analyzed using analysis of variance and Duncan's multiple range test $(\mathrm{P}<0.05)$. Means sharing a common alphabetical symbol did not significantly differ.

to the level of the MDI control (Fig. 4A, D and E). In addition, the protein expression of PPAR $\gamma$ showed the same results as the mRNA levels (Fig. 4B). In addition, the anti-mitotic activity of $\mathrm{C} / \mathrm{EBP} \alpha$ induces 3T3-L1 cell arrest (19). Following the initial phase of DNA replication, 3T3-L1 cells are arrested in the G1 phase of the cell cycle. The arrest coincides with the induction of $\mathrm{C} / \mathrm{EBP} \alpha$ expression (20). These previous studies supported our results that $\mathrm{S} 1 \mathrm{P}$ treatment increases the number of cells $48 \mathrm{~h}$ after MDI induction, which coincides with a lowering of $\mathrm{C} / \mathrm{EBP} \alpha$ expression. However, in the presence of JTE013,
A
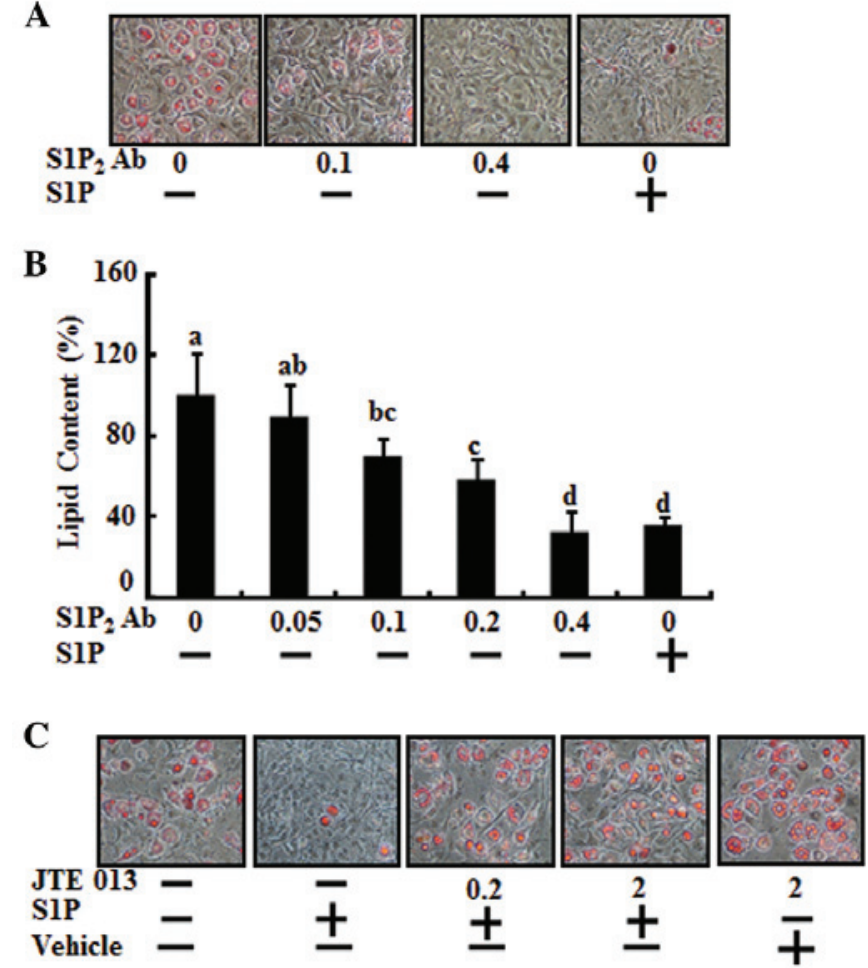

D

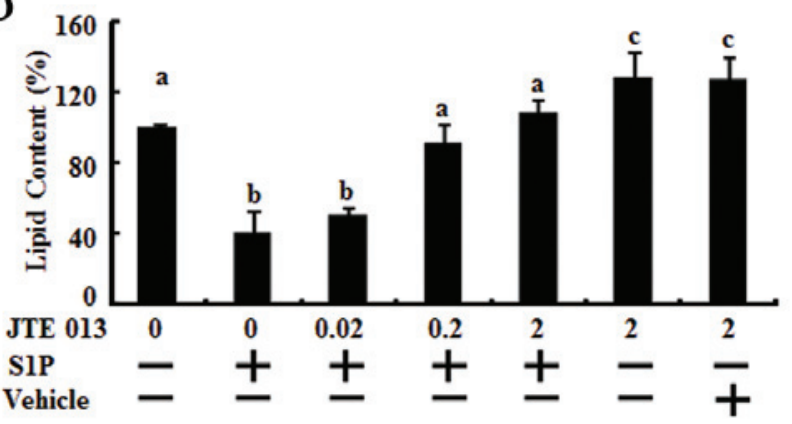

Figure 3. Treatment of sphingosine 1-phosphate receptor $2\left(\mathrm{~S}_{\mathrm{P}}\right)$ antibody inhibits the triglyceride accumulation of S1P whereas the blockade of ${\mathrm{S} 1 \mathrm{P}_{2}}_{2}$ receptor reverses the inhibition of triglyceride accumulation by S1P. (A and B) AdipoRed assays (Lonza, Verviers, Belgium) for triglycerides in 3T3-L1 cells differentiated for 6 days with 3-isobutyl-1-methylxanthine (IBMX), dexamethasone and insulin plus $\mathrm{S}_{1} \mathrm{P}_{2}$ antibody (dose-dependently; $0.05-0.4 \mu \mathrm{g})$, normal goat $\operatorname{IgG}(0.4 \mu \mathrm{g})$ or S1P $10 \mu \mathrm{M}$. On day 7, cells stained by AdipoRed assays were captured with a light microscope (magnification, $\mathrm{x} 200$ ). Fluorescence was measured with excitation of $485 \mathrm{~nm}$ and emission of $572 \mathrm{~nm}$. The bar graphs indicate the mean \pm SEM $(n=3)$. (C) AdipoRed assays for triglycerides in 3T3-L1 cells differentiated for 6 days with IBMX, dexamethasone and insulin plus $10 \mu \mathrm{M} \mathrm{S1P}$ or vehicle control $(0.3 \mathrm{~N} \mathrm{NaOH})$ and/or JTE013, known as $\mathrm{S1P}_{2}$ antagonist, dose-dependently. AdipoRed assays were performed as described in Fig. 3A. (B and D) Fluorescence was measured as described in Fig. 3B. The bar graphs indicate the mean \pm SEM $(n=3)$. The data were analyzed using analysis of variance and Duncan's multiple range test $(\mathrm{P}<0.05)$. Means sharing a common alphabetical symbol did not significantly differ.

the numbers of cells were lowered and the $\mathrm{C} / \mathrm{EBP} \alpha$ expression was reversed similar to MDI induction in the controls (Fig. 4C and 4D). It was observed that cell numbers of the MDI induction were doubled in the control and those of the S1P treatment were similar to the control. There were no significant quantitative differences between the control and MDI induction. MDI induction and S1P co-treatment increased cell numbers effectively compared with MDI treatment alone (Fig. 4C). These 
A

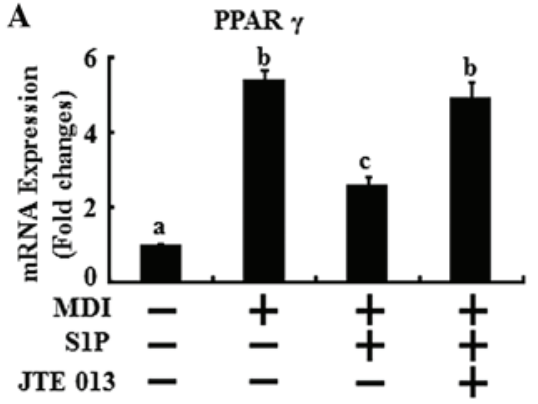

B



C



D



E

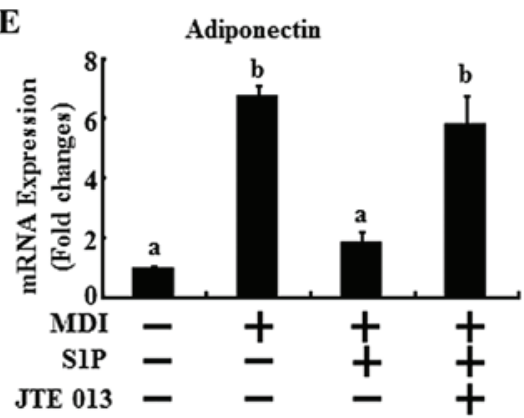

Figure 4. Sphingosine 1-phosphate receptor $2\left(\mathrm{~S}_{\mathrm{P}}\right)$ is correlated with downregulation of peroxisome proliferator-activated receptor $\gamma$ (PPAR $\left.\gamma\right)$, CCAAT/enhancer binding protein $\alpha(\mathrm{C} / \mathrm{EBP} \alpha)$ and adiponectin expression induced by S1P. (A) Preadipocytes were induced to differentiate with $10 \mu \mathrm{M}$ S1P or/and $0.2 \mu \mathrm{M}$ JTE013 and harvested on day 2 during the differentiation period. The mRNA expression of PPAR $\gamma(\mathrm{A}), \mathrm{C} / \mathrm{EBP} \alpha$ (D) and adiponectin (E) was analyzed by real-time polymerase chain reaction. Values are the mean \pm SD of data from three separate experiments; each experiment was performed in triplicate. (B) Preadipocytes were treated as described in Fig. 4A. On day 2, the protein levels of PPAR $\gamma$ were analyzed by western blot analysis using antibodies for PPAR $\gamma$. (C) Day 0 postconfluent 3T3-L1 preadipocytes were treated as described in Fig. 4A. On day 2, the cell number was determined by trypan blue exclusion test, and the absolute cell number was graphed. The experiments were repeatedly performed to confirm the results. The data were analyzed using analysis of variance and Duncan's multiple range test $(\mathrm{P}<0.05)$. Means sharing a common alphabetical symbol did not significantly differ.

results demonstrate that the $\mathrm{S}_{1} \mathrm{P}_{2}$ receptor plays a dominant role in the anti-differentiating action of S1P.

\section{Discussion}

We have shown that treatment with exogenous S1P effectively inhibits adipogenesis by downregulating the expression of adipocyte-specific differentiation markers. Neither the $\mathrm{S}_{1} \mathrm{P}_{1}$ selective agonist (SEW2871) nor the antagonist (W146) affected the adipocyte differentiation function of S1P. By contrast, abrogation of the $\mathrm{S}_{1} \mathrm{P}_{2}$ receptor recovered the impaired differentiation caused by S1P as well as enhancing differentiation. These anti-adipogenic effects of S1P via the $\mathrm{S}_{\mathrm{P}} \mathrm{P}_{2}$ receptor occurred through the regulation of MAPK pathways and the master of adipogenic transcriptional factors.

There is a previous relevant study concerning Sphk-1 and adipogenesis, which reveals that Sphk-1 is induced and S1P content increased in adipogenesis, and that its downregulation (using Sphk-1 inhibitors and siRNA) blocks differentiation (21). In addition, S1P content increased in adipogenesis. However, there was no information as to whether direct treatment of S1P has a pro-adipogenic effect. In addition, there is no information on the adipogenic effect of activating Sphk-1 and whether or not the activation of Sphk-1 promotes adipogenesis or increases S1P content. Therefore, we examined the direct effect of S1P and our results revealed that the direct effect of $\mathrm{S} 1 \mathrm{P}$ exerted an anti-adipogenic effect via $\mathrm{S}_{2} \mathrm{P}_{2}$.

Numerous signaling pathways that are activated in response to the stimulation of cells by S1P are initiated by activation of
S1P-specific receptors. The results of this study revealed that the anti-adipogenic action of S1P was not associated with $\mathrm{S}_{1} \mathrm{P}_{1}$

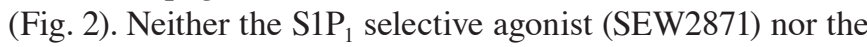
$\mathrm{S}_{1} \mathrm{P}_{1}$ antagonist (W146) affected the inhibition of adipocyte differentiation by S1P. The anti-adipogenic effect of S1P occurred via $\mathrm{S}_{1} \mathrm{P}_{2}$. In addition, the $\mathrm{S} \mathrm{P}_{2}$ selective antagonist significantly reversed the inhibition of S1P during adipocyte differentiation (Fig. 3). A single treatment of JTE013 alone enhanced adipocyte differentiation. The adipogenesis process is tightly controlled by PPAR $\gamma$ and $\mathrm{C} / \mathrm{EBP} \alpha$. PPAR $\gamma$ is the master regulator of adipogenesis. $\mathrm{C} / \mathrm{EBP} \alpha$ induces numerous adipocyte genes directly (22). As a result, as noted in Fig. 4, S1P lowered PPAR $\gamma$ and C/EBP $\alpha$ expression; however, S1P lost its ability to impair PPAR $\gamma$ and $\mathrm{C} / \mathrm{EBP} \alpha$ expression in the abrogation of $\mathrm{S} \mathrm{P}_{2}$ using JTE013 treatment (Fig. 4). These previous studies supported our results that S1P treatment increases the number of cells $48 \mathrm{~h}$ after MDI induction, which coincides with a lowering of $\mathrm{C} / \mathrm{EBP} \alpha$ expression. However, in the presence of JTE013, the numbers of cells were lowered and $\mathrm{C} / \mathrm{EBP} \alpha$ expression was reversed similar to MDI induction in the controls (Fig. 4).

In conclusion, the results of this study demonstrated that exposure of preadipocytes to S1P inhibited their differentiation into adipocytes, as confirmed by a reduction in triglyceride accumulation and a reduction in the expression of adipocyte-specific genes. Therefore, S1P functioned as an anti-adipogenic compound and $\mathrm{S}_{1} \mathrm{P}_{2}$ was shown to be responsible for the anti-adipogenic activity of S1P. This study identifies the activation of $\mathrm{S}_{1} \mathrm{P}_{2}$ receptor as a possible 
mechanism of the anti-adipogenic differentiating action of S1P and suggests that $\mathrm{S}_{1} \mathrm{P}_{2}$ activation may be a therapeutic target for anti-obesity.

\section{Acknowledgements}

This study was supported by a grant from the National Research Foundation of Korea (NRF), funded by the Korean government (2012R1A1B3000463).

\section{References}

1. Hannun YA and Obeid LM: Principles of bioactive lipid signalling: lessons from sphingolipids. Nat Rev Mol Cell Biol 9: $139-150,2008$

2. Olivera A and Spiegel S: Sphingosine-1-phosphate as second messenger in cell proliferation induced by PDGF and FCS mitogens. Nature 365: 557-560, 1993.

3. Spiegel S and Milstien S: Sphingosine-1-phosphate: an enigmatic signalling lipid. Nat Rev Mol Cell Biol 4: 397-407, 2003.

4. Goparaju SK, Jolly PS, Watterson KR, et al: The S1P2 receptor negatively regulates platelet-derived growth factor-induced motility and proliferation. Mol Cell Biol 25: 4237-4249, 2005.

5. Rayalam S, Della-Fera MA and Baile CA: Phytochemicals and regulation of the adipocyte life cycle. J Nutr Biochem 19: 717-726, 2008

6. Lee H, Lee YJ, Choi H, Ko EH and Kim JW: Reactive oxygen species facilitate adipocyte differentiation by accelerating mitotic clonal expansion. J Biol Chem 284: 10601-10609, 2009.

7. Nerurkar PV, Lee YK and Nerurkar VR: Momordica charantia (bitter melon) inhibits primary human adipocyte differentiation by modulating adipogenic genes. BMC Complement Altern Med 10: 34, 2010

8. Yanagiya T, Tanabe A and Hotta K: Gap-junctional communication is required for mitotic clonal expansion during adipogenesis. Obesity (Silver Spring) 15: 572-582, 2007.

9. Hait NC, Oskeritzian CA, Paugh SW, Milstien S and Spiegel S: Sphingosine kinases, sphingosine 1-phosphate, apoptosis and diseases. Biochim Biophys Acta 1758: 2016-2026, 2006.
10. Hannun YA, Luberto $C$ and Argraves KM: Enzymes of sphingolipid metabolism: from modular to integrative signaling. Biochemistry 40: 4893-4903, 2001.

11. Smith ER and Merrill AH Jr: Differential roles of de novo sphingolipid biosynthesis and turnover in the 'burst' of free sphingosine and sphinganine, and their 1-phosphates and $\mathrm{N}$-acyl-derivatives, that occurs upon changing the medium of cells in culture. J Biol Chem 270: 18749-18758, 1995.

12. Cremesti AE, Goni FM and Kolesnick R: Role of sphingomyelinase and ceramide in modulating rafts: do biophysical properties determine biologic outcome? FEBS Lett 531: 47-53, 2002.

13. Spiegel S and Milstien S: Sphingosine 1-phosphate, a key cell signaling molecule. J Biol Chem 277: 25851-25854, 2002.

14. Johnstone ED, Chan G, Sibley CP, Davidge ST, Lowen B and Guilbert LJ: Sphingosine-1-phosphate inhibition of placental trophoblast differentiation through a G(i)-coupled receptor response. J Lipid Res 46: 1833-1839, 2005.

15. Goetzl EJ, Wang W, McGiffert C, Liao JJ and Huang MC: Sphingosine 1-phosphate as an intracellular messenger and extracellular mediator in immunity. Acta Paediatr Suppl 96: 49-52, 2007.

16. He X, H'Ng S C, Leong DT, Hutmacher DW and Melendez AJ: Sphingosine-1-phosphate mediates proliferation maintaining the multipotency of human adult bone marrow and adipose tissue-derived stem cells. J Mol Cell Biol 2: 199-208, 2010.

17. Schuppel M, Kurschner U, Kleuser U, Schafer-Korting M and Kleuser B: Sphingosine 1-phosphate restrains insulin-mediated keratinocyte proliferation via inhibition of Akt through the S1P2 receptor subtype. J Invest Dermatol 128: 1747-1756, 2008.

18. Moon MH, Jeong JK, Seo JS, et al: Bisphosphonate enhances TRAIL sensitivity to human osteosarcoma cells via death receptor 5 upregulation. Exp Mol Med 43: 138-145, 2011.

19. Ntambi J and Young-Cheul K: Adipocyte differentiation and gene expression. J Nutr 130: 3122S-3126S, 2000.

20. Reichert M and Eick D: Analysis of cell cycle arrest in adipocyte differentiation. Oncogene 18: 459-466, 1999.

21. Hashimoto T, Igarashi J and Kosaka H: Sphingosine kinase is induced in mouse 3T3-L1 cells and promotes adipogenesis. J Lipid Res 50: 602-610, 2009.

22. Rosen ED and MacDougald OA: Adipocyte differentiation from the inside out. Nat Rev Mol Cell Biol 7: 885-896, 2006. 